\title{
EUTOMIA
}

Revista de Literatura e Linguística

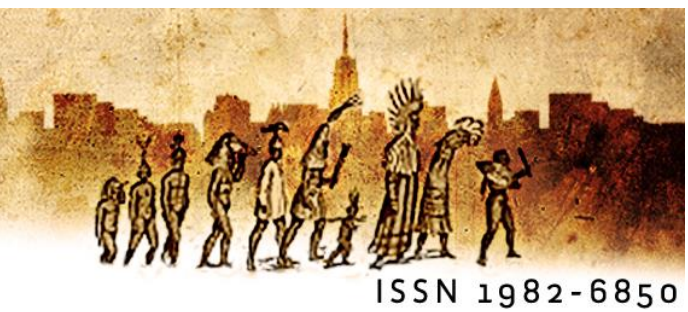

\section{As potencialidades dos tipos discursivos na compreensão dos efeitos da aprendizagem epistêmica no desenvolvimento em uma formação científica de caráter longitudinal}

\section{The potentialities of discursive types in the understanding of the developmental effects of epistemic learning in a longitudinal scientific educational process}

Resumo: Este artigo tem como objetivo apresentar uma reflexão sobre as potencialidades dos tipos discursivos na compreensão dos efeitos da aprendizagem epistêmica no desenvolvimento de mestrandos em uma formação científica. Especificamente, buscamos verificar como os tipos discursivos permitem compreender o desenvolvimento do pesquisador nos textos escritos e versões produzidos ao longo do mestrado acadêmico e, também, compreender as relações possíveis entre a aprendizagem epistêmica, desenvolvimento do pesquisador e a construção dos saberes. Nossa base teórica é composta por conceitos advindos do Interacionismo social (VIGOTSKI, 2004 [1926], 2007 [1935], 2009 [1934], 2013 [1927]) e do Interacionismo sociodiscursivo (BRONCKART, 1999, 2006, 2008; BULEA; BRONCKART, 2008). Nossos dados são excertos de textos escritos e versões (projeto de pesquisa, relatório de qualificação e dissertação de mestrado) produzidos por três mestrandos, ao longo do processo do mestrado acadêmico, e comentados por seus orientadores. Tratase, portanto, de um estudo longitudinal. Como resultados, verificamos que o tipo discursivo misto interativo-teórico nas versões comentadas permite que vejamos um "diálogo" entre os mestrandos e os orientadores, no qual ocorrem processos de aprendizagem epistêmica (BOTA, 2018). Essa aprendizagem pode proporcionar um ganho para o pensamento científico através da criação de possíveis novos saberes.

Palavras-chave: Desenvolvimento; Aprendizagem epistêmica; Tipos discursivos; Saberes.

Abstract: This article aims to present a reflection on the potentialities of the discursive types in the understanding of the developmental effects of learning in a longitudinal scientific educational process. Specifically, we seek to verify how the discursive types allow to understand the development of the researcher in the written texts and versions 
produced throughout the academic master's degree and, also, to understand the possible relations between epistemic learning, development of the researcher and the construction of knowledge. Our theoretical basis is composed of concepts derived from social Interactionism (VIGOTSKI, 2004 [1926], 2007 [1935], 2009 [1934], 2013 [1927]) and sociodiscursive Interactionism (BRONCKART, 1999, 2006, 2008; BULEA; BRONCKART, 2008). Our research data are excerpts from written texts and versions (research project intermediate report and master's thesis) produced by three master's students, throughout the academic master's process, and commented by their advisors. It is, therefore, a longitudinal study. As a result, we found that the mixed interactivetheoretical discursive type in the commented versions allows us to see a "dialogue" between master's students and advisors, in which epistemic learning processes occur (BOTA, 2018). This learning can provide a gain for scientific thinking through the creation of possible new knowledge.

Keywords: Development; Epistemic learning; Discursive types; Knowledge.

\section{Introdução}

Estimulados por este dossiê temático sobre desenvolvimento humano e aprendizagem no âmbito da educação formativa, propomo-nos neste artigo a contribuir com esses estudos, discutindo a questão pelo prisma do desenvolvimento do pesquisador na formação durante o processo do mestrado acadêmico, em relação à aprendizagem epistêmica e à mediação pela linguagem.

Essa reflexão advém das questões abordadas em nossa pesquisa de doutorado (FERREIRA-SANTOS, 2020), que foi concluída recentemente e teve como objetivo investigar, de forma longitudinal, o desenvolvimento do pesquisador durante o processo formativo do mestrado acadêmico. De forma mais específica, buscamos verificar qual é o papel da linguagem nesse processo por meio da análise das versões comentadas e finais dos textos escritos (projeto de pesquisa, relatório de qualificação e dissertação de mestrado) e dos textos orais (exame de qualificação e defesa de mestrado) prescritos pelo dispositivo formativo.

Em nossa pesquisa, assumimos os pressupostos teóricos do Interacionismo social, tal como desenvolvido por Vigotski (2004 [1926], 2007 [1935], 2009 [1934], 2013 [1927]) e seus colaboradores, e do Interacionismo sociodiscursivo proposto por Bronckart (1999, 2006, 2008). Desse modo, nossa contribuição neste artigo tem como base, além dos pressupostos vigotskianos, os estudos sobre aprendizagem, desenvolvimento e mediação pela linguagem desenvolvidas contemporaneamente por pesquisadores do ISD. 
O conceito de "desenvolvimento", de modo geral, e também o entendimento dessa noção advinda da perspectiva vigotskiana, incita diversos debates e é periodicamente retomado à luz dos resultados de novas investigações científicas sobre a formação de adultos. Evidência disso é o questionamento feito por Friedrich, Hofstetter e Schneuwly (2013, p.9), "Une science du développment est-elle possible?"1 ${ }^{1}$, devido ao fato de que inúmeros pesquisadores que problematizam esse tema.

Retomando o conceito de desenvolvimento, Bronckart (2013 [2008], p.91), por exemplo, propõe a distinção de três níveis: desenvolvimento dos conceitos elaborados pelas ciências, das capacidades de ação, e da identidade das pessoas. Em adição, Bronckart (2013 [2008], p.104) afirma que o desenvolvimento pode ocorrer, quando há uma reestruturação psíquica positiva, isto é, quando há apropriação-interiorização do debate interpretativo do meio social, que se traduz pela atribuição de novas significações desse debate.

Por sua vez, Schneuwly (2013, p.324) entende que o desenvolvimento implica a construção de novos sistemas psíquicos e pode ocorrer "quand la transformation (par exemple de l'écrit) fait partie d'une transformation du système de la personne". ${ }^{2}$ Em comparação, a aprendizagem pode ocorrer "quand la transformation des compétences ne font pas partie d'une transformation de la personne". ${ }^{3}$ Ademais, Schneuwly (2013, p.325) compreende que a pesquisa científica sobre o desenvolvimento de adultos tem ainda um futuro promissor e, para ele, a tese vigotskiana da diferença fundamental entre desenvolvimento da criança e do adulto constitui um ponto de partida necessário, assim como o conceito de desenvolvimento através da reconfiguração de sistemas psíquicos.

No que concerne à formação para desenvolvimento de adultos, Bota et al (2006, p.88) distinguem dois tipos de abordagens. A primeira tem o objetivo de transmitir os saberes e os procedimentos formalizados, colocando-os à disposição dos formandos, que buscam apropriar-se deles; a segunda tem como objeto o agir real dos formandos, utilizando procedimentos dos quais decorrem um "efeito inteligível", que visa a favorecer o desenvolvimento do seu estatuto de "ator" autônomo e criativo. Para Bota et al (2006, p.88), a questão crucial da formação de adultos reside na articulação eficaz das duas

\footnotetext{
1 “Uma ciência do desenvolvimento é possível?”. (Tradução nossa)

2 "Quando a transformação (por exemplo da escrita) faz parte de uma transformação do sistema da pessoa" (Tradução nossa).

3 "Quando a transformação das competências não faz parte de uma transformação do sistema da pessoa" (Tradução nossa).
} 
abordagens citadas. Em nosso caso, neste artigo, analisamos um processo formativo real o mestrado acadêmico - no qual os mestrandos tinham que se apropriar dos conceitos científicos formalizados nas teorias em que eles se baseavam, sendo auxiliados para isso por seus orientadores, que emitiam comentários verbais nos textos produzidos pelos estudantes.

Na esteira do ISD, no que tange ao papel das verbalizações e sua relação com os processos de aprendizagem e desenvolvimento, as pesquisas de Bulea (2010) e Bota (2018) mostraram as potencialidades tanto praxiológicas, quanto epistêmicas dos tipos discursivos, categoria do ISD que designa macroestruturas psicolinguísticas, nas quais são colocadas em interface as representações individuais e as representações coletivas. No registro praxiológico, Bulea (2010, p.75) mostrou que os tipos discursivos são suscetíveis, quando combinados com o conteúdo temático que depende do agir, de gerar "cortes interpretativos", os quais têm uma forma de coerência identificável e que permitem a compreensão dos efeitos da interpretação da atividade no desenvolvimento.

No registro epistêmico, Bota (2018) mostrou que é no nível do texto, mais precisamente dos tipos discursivos, que ocorrem os processos de abstração e generalização. Em outras palavras, é no nível dos tipos discursivos que atualizam e se reelaboram os conhecimentos humanos, pois eles são concebidos como espaços de construção, de transformação e aprendizagem das formas de desdobramento do pensamento humano (BOTA, 2018, p.182).

Tendo em vista as pesquisas acima descritas, nosso artigo tem por objetivo discutir o registro epistêmico dos tipos discursivos em uma práxis formativa, por meio dos textos escritos e versões (projeto de pesquisa, relatório de qualificação e dissertação de mestrado) produzidos por três estudantes, ao longo do processo do mestrado acadêmico, e comentados por seus orientadores.

Em nosso levantamento sobre as pesquisas brasileiras que investigaram o processo do mestrado acadêmico (FERREIRA-SANTOS, 2020) ${ }^{4}$, percebemos, em geral, que esses trabalhos se valem de questionários; focam-se na análise dos planos globais dos conteúdos temáticos dos textos; interessam-se por avaliar um programa de pós-graduação;

\footnotetext{
${ }^{4}$ A busca foi realizada na Biblioteca Digital Brasileira de Teses e Dissertações.
} 
desconsideram a temporalidade do processo do mestrado; parecem não investigar a construção dos saberes e negligenciam o valor das versões dos textos nas investigações.

Levando em conta essa lacuna e tendo em vista as discussões acima apresentadas sobre desenvolvimento humano e aprendizagem no âmbito da educação formativa, estabelecemos os seguintes objetivos específicos para este artigo:

a) Verificar como os tipos discursivos permitem discutir o desenvolvimento do pesquisador nos textos escritos e versões produzidos ao longo do mestrado acadêmico.

b) Compreender as relações possíveis entre a aprendizagem epistêmica, o desenvolvimento do pesquisador e a construção dos saberes.

Quanto à organização deste artigo, exporemos, primeiramente, os conceitos centrais pelos quais guiaremos nosso raciocínio teórico-analítico e que nos auxiliarão na discussão dos resultados alcançados. Em seguida, descreveremos nossos materiais e o método de análise adotado em nossa pesquisa de doutorado. Por fim, mostraremos alguns excertos para ilustrar a análise, e as discussões dela decorrentes.

\section{Fundamentação teórica}

Em nossa pesquisa, adotamos o Interacionismo sociodiscursivo (BRONCKART, 1999, 2006, 2008) como base teórica. O ISD é uma corrente do Interacionismo social, sobretudo dos trabalhos desenvolvidos por Vigotski (2004 [1926], 2007, 2009 [1934], 2013 [1927]), por isso faremos algumas considerações sobre os estudos vigotskianos acerca da relação entre aprendizagem e desenvolvimento, bem como entre o pensamento e a linguagem.

\subsection{Interacionismo social: desenvolvimento, aprendizagem e formação dos conceitos}

"A pedra que os edificadores rejeitaram, se tornou a pedra angular". Com esta epígrafe religiosa, Vigotski (2013 [1927], p.259) inicia o seu célebre texto sobre o significado histórico da crise em psicologia, instigando o leitor a pensar e a decifrar o significado das alegorias contidas na frase bíblica. Páginas à frente, o autor (2013 [1927], p.261-262) permite compreender que a "pedra angular" é o "homem" (o humano), o qual para Vigotski deveria ser o centro das investigações científicas, especialmente na psicologia.

Eutomia, Recife, 27(1): 99-120, Out. 2020 
Em outras palavras, o humano e suas práticas seriam a "chave" para a compreensão dos processos do seu próprio desenvolvimento, em oposição à visão dos "edificadores", ou seja, dos cientistas à época, os quais estudavam os comportamentos humanos em equivalência aos comportamentos animais, adotando conceitos da Biologia. Sintetiza Vigotski (2013 [1927], p.262), "somente podemos compreender cabalmente uma determinada etapa do processo de desenvolvimento - incluindo o próprio processo - se conhecemos o resultado ao qual se dirige o desenvolvimento, a forma final que adota e a maneira como se realiza".

A crise diagnosticada por Vigotski o levou (e leva-nos até os dias atuais) a essa discussão aplicada ao âmbito da educação, pois para Vigotski (2004 [1926], p.10), "o processo educacional é um processo psicológico [...] A educação acaba significando sempre a modificação do comportamento hereditário e a inoculação de novas formas de reação". A forma como os processos educacionais funcionavam na "inoculação de novas formas de reação", isto é, na aprendizagem de novas formas de comportamento, não era pacífica no contexto russo das primeiras décadas do séc. $X X$, pois a ideia predominante era aquela que defendia a preeminência do desenvolvimento cognitivo na compreensão dos processos de aprendizagem, seja considerando esta independente do processo de desenvolvimento, seja postulando sua dependência ou equivalência a ele (VIGOTSKI, 2004 [1926], p.466-471). De uma forma ou outra, o caráter metodológico materialista (do comportamento humano), dialético e biossocial dos processos educativos eram negligenciados.

A partir desse arcabouço conceitual, Vigotski (2007 [1935], p.103) vai propor o seguinte raciocínio na discussão sobre a relação entre os processos de desenvolvimento e aprendizagem:

Resumindo, o aspecto mais essencial de nossa hipótese é a noção de que os processos de desenvolvimento não coincidem com os processos de aprendizado. Ou melhor, o processo de desenvolvimento progride de forma mais lenta e atrás do processo de aprendizado; desta sequenciação resultam, então, as zonas de desenvolvimento proximal. Nossa análise modifica a visão tradicional, segundo a qual, no momento em que uma criança assimila o significado de uma palavra, ou domina uma operação tal como a adição ou a linguagem escrita, seus processos de desenvolvimento estão basicamente completos.

Em vista do caráter metodológico acima, para os estudiosos do grupo de Vigotski, o ser humano, ao nascer, encontra-se em um ambiente onde existem as leis biológicas da 
própria espécie, mas também leis sociais, que diferenciam o humano de todos os outros animais. Por meio de sua atividade produtiva o homem construiu "produtos" tanto mentais, quanto materiais, que foram se modificando ao longo do desenvolvimento humano (a ontogênese), além de capacidades não inatas, ou funções psicológicas superiores, desenvolvidas no processo da ontogênese (LEONTIEV, 2005 [1959], p.90).

De que modo as funções psicológicas superiores, como o pensamento, por exemplo, são apropriadas pelos indivíduos? Leontiev (2005 [1959], p.93) faz a si próprio pergunta semelhante e a responde, afirmando que a existência da linguagem no ambiente humano favorece a aprendizagem das funções superiores, pois os pares mais experientes (pais e educadores, entre outros) guiam injuntivamente o par menos experiente à execução de ações e operações cuja finalidade é a aprendizagem de determinado saber.

A linguagem, que também é tomada como uma função psicológica superior, recebe grande atenção do grupo de Vigotski (2009 [1934]), sobretudo na sua relação com o pensamento. Como resultado dos estudos de Vigotski em colaboração com Sakharov, realizado tanto com crianças, quanto com adultos, estabeleceu-se um percurso genético do desenvolvimento do pensamento conceitual, que é dividido em três fases: pensamento sincrético, pensamento por complexos e pensamento por conceitos (VIGOTSKI, 2009 [1934], p.174). Exporemos mais detalhadamente as duas últimas fases. A primeira, o "pensamento sincrético", pode ser definida pela utilização das palavras de acordo com a percepção do indivíduo, sendo que o significado das palavras é vago, altamente instável e construído por nexos subjetivos (VIGOTSKI, 2009 [1934], p.175).

No segundo estágio de formação dos conceitos ou "pensamento por complexos", o conjunto de objetos dessemelhantes reunidos sem qualquer base passa a ser unificado não mais por nexos subjetivos, mas por nexos objetivos que efetivamente existem entre esses objetos, formando um "complexo". O "complexo" é a generalização formada por vínculos fatuais e fortuitos, podendo ser nomeado com um "nome de família", porém esses vínculos são diferentes daqueles de um conceito verdadeiro, os quais são generalizados uniformemente (VIGOTSKI, 2009 [1934], p.180).

Nesse estágio, Vigotski (2009 [1934], p.190) e Sakharov descobrem a última fase do "pensamento por complexos", nomeada por eles de "pseudoconceitos". Os pseudoconceitos formam o elo entre o pensamento por complexos e os verdadeiros 
conceitos. Quando utilizados, podem parecer semelhantes a um conceito verdadeiro, porém são psicologicamente diferentes. O agrupamento realizado pela formação do pseudoconceito é feito pela semelhança concreta visível. O "pensamento por complexos", segundo Vigotski ([1934] 2009, p.180), aparece constantemente na linguagem dos adultos, que estão longe de pensarem somente por conceitos verdadeiros.

O terceiro estágio de formação, o último, é chamado por Vigotski ([1934] 2009) de "pensamento por conceitos". Para a formação do verdadeiro conceito, é necessária, além da generalização de elementos semelhantes, a discriminação e abstração desses elementos fora do vínculo concreto e fatual em que são dados na experiência, a fim de que ocorra uma síntese (VIGOTSKI, 2009 [1934]).

Devido ao papel importante que a linguagem adquire nos estudos vigotskianos, exporemos a seguir outra base teórica do nosso trabalho: o interacionismo sociodiscursivo, cujo objetivo central é estudar o papel do funcionamento discursivo no desenvolvimento (BRONCKART, 2006, 2008).

\subsection{ISD: análise da linguagem, mediações formativas e aprendizagem epistêmica}

Como expusemos anteriormente, Vigotski e seu grupo de colaboradores teorizaram várias questões acerca do papel da linguagem no desenvolvimento humano e da relação do pensamento e linguagem. Entretanto, após a morte prematura de Vigotski, abriu-se um campo de investigação acerca do papel real e efetivo das produções linguageiras no desenvolvimento humano. Nessa perspectiva, nas últimas décadas do séc. $X X$, surge o interacionismo sociodiscursivo, uma corrente teórica em continuidade até os dias de hoje, que retoma algumas questões de pesquisa iniciadas pelo interacionismo social.

Assumindo os pressupostos básicos do Interacionismo social, o ISD adere ao esquema de desenvolvimento proposto por Vigotski: a) a especificidade da espécie humana que, diferentemente de outras espécies, é capaz de realizar atividades coletivas mais organizadas e complexas; b) a complexidade dessas atividades coletivas condicionou a emergência de um mecanismo de cooperação para agir, ou seja, a linguagem, que permite planificar, regular e avaliar outras atividades ; c) essa atividade de linguagem é produtora de unidades semióticas compartilhadas e coletivas ; d) é a apropriação e interiorização dessas 
unidades semióticas socializadas que provocam a transformação do psiquismo dos indivíduos, possibilitando a constituição de mundos de obras e de culturas (BRONCKART, 2008, p. 52).

Segundo Bronckart (2006), para o ISD, o problema da linguagem é absolutamente central, já que as práticas de linguagem situadas são instrumentos do desenvolvimento humano, tanto em relação aos conhecimentos e aos saberes quanto em relação às capacidades do agir.

Explicamos, na seção anterior, que uma das preocupações de Vigotski e seu grupo foi a discussão a respeito das formas de transmissão dos saberes, ou seja, o modo pelo qual os membros mais experientes do grupo integram e transmitem os produtos materiais e mentais da cultura. No âmbito do interacionismo sociodiscursivo, essa questão também é discutida a partir dos trabalhos de Vigotski, investigando-se os "sistemas formativos". Conforme detalham Bulea, Bota e Bronckart (2006, p.51), os "sistemas formativos" podem ser agrupados em processos de educação desenvolvidos no meio escolar ou em outros processos nos quais os indivíduos mais experientes integram os recém-chegados no conjunto de pré-construídos coletivos, desenvolvendo conjuntamente atividades e mostrando as normas e os valores sociais, quando lhes são fornecidos comentários verbais sobre essas atividades.

Desse modo, é possível examinar os processos de um sistema formativo por meio dos comentários verbais nas interações formativas neles realizados entre os pares mais experientes e os novatos. Tomando-se como exemplo o sistema para a formação em pesquisa científica no contexto brasileiro, encontramos processos de formação institucionalizados, como o Mestrado e o Doutorado, além da Iniciação Científica, no âmbito da graduação e já estudada por nós (SANTOS, 2016).

Para a análise das interações verbais e dos textos, o ISD (BRONCKART, 1999, 2006) se baseia na proposta metodológica proposta por Volóshinov (2010 [1929]) pela qual é necessário se examinar, primeiramente, o quadro contextual no qual a interação se realiza, composto de parâmetros físicos e sociossubjetivos. Posteriormente, segundo Bronckart (1999, 2006), analisa-se a infraestrutura geral do texto, composta pelo plano mais geral, isto é, a organização do conjunto dos conteúdos temáticos, e pelos tipos discursivos, além das sequências textuais. Depois, os mecanismos de textualização (conexão, coesão nominal e 
coesão verbal) e, por fim, os mecanismos de responsabilização enunciativa (vozes e modalizações). A seguir, enfocaremos o conceito de tipos discursivos, que é a categoria utilizada em nossa análise.

Os tipos discursivos são macroestruturas psicolinguísticas, infraordenados em relação aos gêneros textuais, que comportam um conjunto de operações linguísticas e mobilizam, quando acionados, formas mentais ou raciocínios (BRONCKART, 2006, p.154). Conforme entendem Bronckart (2006) e Bulea e Bronckart (2008), os tipos discursivos desenvolvem diversas formas de raciocínio humano: raciocínio causal/temporal (no relato interativo e narração), raciocínio prático do senso comum (no tipo discurso interativo) e raciocínio lógico (no tipo de discurso teórico).

Na verdade, segundo Bronckart (2006), é no nível dos tipos discursivos que se implementam os processos de mediação que contribuem para o desenvolvimento das propriedades principais das pessoas (como a construção da identidade, a inserção no tempo, o domínio dos raciocínios, entre outros), pois, se por um lado permitem a mediação de processos mentais - os raciocínios - por outro ela só é possível pelas propriedades do sistema da língua, que limita fortemente a mediação. Assim, a mediação pela linguagem se constitui como um processo de desenvolvimento fundamental, na medida em que é por meio dela que se transmite as grandes formas da operatividade do pensamento humano.

Há quatro tipos discursivos: o "discurso teórico" e o "discurso interativo" referentes ao mundo discursivo da ordem do expor, e os tipos discursivos "narração" e "relato interativo" referentes à ordem do narrar (BRONCKART, 1999). Trataremos dos dois tipos discursivos da ordem do expor, pois são eles que nos permitem interpretar nossos dados. $O$ tipo discursivo interativo possibilita a criação de segmentos nos quais há implicação conjunta dos participantes da interação verbal, que trocam informações entre si, como verificamos em sequências dialogais orais ou escritas. Por essa razão, encontramos, no discurso interativo, dêiticos pessoais, espaciais e temporais, além de marcadores conversacionais e os tempos verbais presente e passado composto (BRONCKART, 1999).

O tipo discursivo teórico, por sua vez, pode criar um mundo discursivo em que não há implicação do agente produtor do texto e apagamento dos parâmetros de produção dos textos. Encontramos geralmente os tempos verbais presente e passado composto, como também o presente gnômico, além da presença de inúmeros organizadores lógico- 
argumentativos, grande número de modalizações lógicas e de anáforas nominais; no mais, verificamos procedimentos de referência (metatextual, intratextual e intertextual) ao próprio texto ou ao intertexto científico.

Os raciocínios constroem mundos discursivos de linguagem, nos quais são colocadas em interface as representações individuais e as representações coletivas. Em nossa pesquisa (FERREIRA-SANTOS, 2020), constatamos que os tipos discursivos podem funcionar como uma categoria relevante para a compreensão da mediação formativa em interações verbais, em uma formação longitudinal, como é o caso do mestrado acadêmico.

Na perspectiva do ISD (BULEA, BOTA e BRONCKART 2006), os pré-construídos coletivos, como os verdadeiros conceitos, por exemplo, não podem se autoproduzir, pois na perspectiva vigotskiana o conceito verdadeiro pode ser comparado, segundo Bota (2018), a um "diamante esculpido", logo há "filigranas" constituintes a serem aprendidas pelos formandos. Desse modo, as capacidades epistêmicas não são desenvolvidas naturalmente, pois os conceitos científicos só podem ser apropriados se houver uma aprendizagem epistêmica para tal (BOTA, 2018).

Nesse sentido, esse tipo de aprendizagem deve ser produzido necessariamente dentro de uma mediação formativa, pois ele não pode emergir espontaneamente ou se autoproduzir no aprendiz , (BOTA, 2018, p.224). Em relação à capacidade que o "aprendiz" - os mestrandos em formação no nosso caso - adquire para fazer interagir o pensamento e a linguagem, a fim de se apropriar dos conceitos e raciocínios disponibilizados pelo dispositivo de formação, pode apresentar, segundo Bota (2018, p.225), três níveis de aprendizagem epistêmica: superficial, estrutural e funcional.

No nível da aprendizagem superficial, os novos signos são interiorizados eventualmente com traços residuais dos seus valores terminológicos-conceituais, mas sem os religar ao processo de generalização. Na aprendizagem estrutural, os signos são interiorizados em algumas das suas funções generalizantes e o aprendiz reconstrói parcialmente o sistema de conceitos propostos pelo dispositivo de formação. Essa aprendizagem tem um caráter reprodutivo-local. Na aprendizagem funcional, o processo de aprendizagem permite não somente a uma produção de certas conexões pontuais (ou momentâneas) entre o pensamento e a linguagem, mas a uma capacidade permanente de realizar tais conexões, que afeta outros conhecimentos interiorizados anteriormente. Nesse 
caso, o aprendiz reconstrói um sistema de conceitos aberto, podendo "ultrapassar" seus atributos, a fim de "realimentar" o sistema (BOTA, 2018, p.225).

\section{Metodologia da Pesquisa}

Nosso contexto mais geral de pesquisa é a Universidade de São Paulo, mais especificamente a Faculdade de Filosofia, Letras e Ciências Humanas, e os programas de pós-graduação que coexistem nesse espaço. Para encontrarmos nossos sujeitos de pesquisas, elaboramos um questionário para verificar: - quais mestrandos consentiam em participar do estudo; - quais estavam num estágio da pesquisa que nos permitiria ter os dados de que necessitávamos. Após a aplicação de um questionário, três mestrandos se mostraram aptos a serem os participantes de nosso estudo. Eles pertenciam a três distintos programas de pós-graduação da Faculdade de Letras, que são eles: Estudos linguísticos, literários e tradutológicos em Francês; Filologia e Língua Portuguesa; Língua e Literatura Italiana.

Os três participantes estavam elaborando as suas pesquisas quando aceitaram participar de nosso estudo, concedendo-nos seus textos e versões dos projetos de pesquisa, relatórios de qualificação e, posteriormente, tivemos acesso às dissertações de mestrado e versões.

Neste artigo, como explicamos na introdução, focaremos em alguns excertos mais representativos das nossas análises dos textos escritos. Visto que estávamos trabalhando com as versões dos textos produzidos pelos estudantes, recebemos uma vultosa quantidade de dados escritos, os quais tivemos que uniformizar metodologicamente. Em linha gerais, selecionamos as versões com mais comentários dos orientadores e que guardavam, também, comentários de versões anteriores.

Dentre esses comentários, excluímos aqueles relacionados a erros gramaticais, ortográficos, entre outros, pois interessavam-nos os comentários acerca dos conceitos teóricos usados pelos estudantes, na seção de "Fundamentação teórica" e, eventualmente, dos novos saberes elaborados por eles, na seção de "Análises e resultados".

Apontamos, na seção anterior, a nossa adesão ao ISD tanto no plano teórico, quanto da análise metodológica. Dentre as categorias de análise propostas pelo ISD, selecionamos, 
neste artigo, os tipos discursivos, particularmente o discurso interativo e o discurso teórico (BRONCKART, 1999, 2006) que foram encontrados em nossos dados e que possibilitam uma reflexão sobre o desenvolvimento dos mestrandos nesse processo formativo. $\mathrm{Na}$ análise, levaremos em conta o processo de modificação, reformulação dos raciocínios lógicos produzidos pelos estudantes, após os comentários verbais de seus orientadores. Em nossa pesquisa isso é relevante, pois estamos trabalhando com as versões dos textos escritos, as quais contêm diversos comentários dos orientadores, logo é pertinente para nós discutir o aspecto formativo dessas intervenções, contrastando com as mudanças apresentadas no raciocínio produzido nas versões finais dos textos, após os comentários formativos.

Outrossim, posto que estamos analisando o desenvolvimento do pensamento científico, os aportes de Vigotski ([1934] 2009) relacionados com os processos de formação dos conceitos, são relevantes para a interpretação das análises dos tipos discursivos. Esse procedimento analítico-interpretativo pode nos apontar questões pertinentes para a discussão entre o uso da mediação pela linguagem, os três níveis de aprendizagem epistêmica propostos por Bota (2018) e a construção de novos saberes.

\section{Análise dos tipos discursivos nas interações formativas em excertos escritos}

Como mencionamos, analisamos, em nossa pesquisa de doutorado (FERREIRASANTOS, 2020), os textos produzidos obrigatoriamente pelos alunos do mestrado e procuramos compreender as mudanças entre eles, sabendo que foram produzidos em momentos diferentes do mestrado acadêmico: momento inicial, intermediário e final. Desse modo, mostraremos algumas análises de excertos das versões comentadas dos projetos de pesquisa (momento inicial), relatórios de qualificação (momento intermediário) e dissertações de mestrado (momento final), seguidos dos mesmos segmentos nas versões finais de cada um dos três gêneros textuais. Constatamos que cada momento do processo de mestrado contém uma especificidade na aprendizagem epistêmica.

De modo geral, os resultados de nossas análises apontam que os tipos discursivos podem ser considerados como um índice psicolinguageiro pelo qual podemos compreender as representações individuais dos estudantes, na compreensão dos conceitos científicos, em 
interface com as representações coletivas, desveladas nos comentários dos orientadores ${ }^{5}$. Em outras palavras, percebemos que os comentários dos orientadores, que são os pares mais experientes das interações formativas, possibilitam a aprendizagem epistêmica (BOTA, 2018). Em outras palavras, os estudantes iniciam um processo de aprendizagem dos conceitos utilizados em uma determinada perspectiva teórica.

Como já expusemos, os raciocínios acionados pelos tipos discursivos constroem mundos discursivos de linguagem, nos quais são colocadas em interface as representações individuais e as representações coletivas; além disso, segundo Bronckart (2006) e Bulea e Bronckart (2008), o tipo discursivo teórico aciona um raciocínio lógico Tomando essa ideia para o nosso contexto de pesquisa, levantamos a hipótese de que os comentários verbais dos orientadores, em discurso interativo, podem intervir no mundo discursivo criado pelo raciocínio lógico dos estudantes, na exposição escrita dos conceitos científicos, gerando as modificações constatadas nas versões finais.

As versões comentadas dos textos escritos, dessa forma, contêm "diálogos" entre os orientadores e os mestrandos, criando segmentos do tipo misto interativo-teórico ${ }^{6}$. Verificamos, assim, que esse "diálogo" pode ter a função de intervir no raciocínio lógico dos estudantes, a fim de que as suas representações individuais estejam mais adequadas às representações coletivas.

Como veremos no excerto abaixo, as análises dos projetos de pesquisa mostram que a fase inicial do mestrado, conforme os comentários dos orientadores, parece evidenciar uma primeira aprendizagem dos conceitos. Podemos dizer que os mestrandos estavam em um nível inicial da aprendizagem epistêmica, isto é, mais especificamente, uma aprendizagem superficial (BOTA, 2018, p.225). Constatamos o início de um processo pelo qual os estudantes poderiam desenvolver uma capacidade para fazer a linguagem e 0 pensamento interagirem de uma nova maneira, a fim de se apropriar dos conceitos e raciocínios científicos. Entretanto, trata-se de uma aprendizagem somente verbal, que não produz nenhuma capacidade "complexa", haja vista que os estudantes interiorizam os novos signos eventualmente com traços residuais do seus valores terminológicosconceituais.

\footnotetext{
${ }^{5}$ Nos excertos, os comentários dos orientadores aparecerem entre colchetes: [comentário].

${ }^{6}$ Para Bronckart (1999, p.192), o tipo discursivo misto interativo-teórico pode ser encontrados em exposições orais científicas ou escritas.
} 
Acompanhemos, abaixo, a análise do Exemplo 1.

\section{Exemplo 1 (Estudante 1)}

\begin{tabular}{|l|l|}
\hline \multicolumn{3}{|c|}{ Fundamentação Teórica } \\
\hline \multicolumn{1}{|c|}{ Versão comentada } & \multicolumn{1}{|c|}{ Versão Final } \\
\hline "Os gêneros [cuidado pq Bakthin não usa o & "Os gêneros do discurso são [...] enunciados \\
termo gênero textual] são [...] enunciados & relativamente estáveis presentes em cada \\
relativamente estáveis presentes em cada & esfera da atividade humana e sócio- \\
esfera da atividade humana e sócio- & historicamente construídos (BAKHTIN, \\
historicamente construídos (BAKHTIN, & 1953)." \\
1953)." &
\end{tabular}

\section{Quadro 1 - Análise da fase inicial do mestrado}

No excerto da versão comentada, encontramos características linguísticas típicas do tipo discursivo misto interativo-teórico. Verificamos o uso do presente gnômico ("são" e "usa"), modalizador com sentido imperativo ("Cuidado"), cujo efeito pressupõe um "diálogo" com o destinatário, modalização lógica expressa por uma asserção ("Bakhtin não usa"), além de organizadores lógicos ("e" e "porque").Esse comentário do orientador gera um conflito, no sentido vigotskiano, pois coloca em dúvida a compreensão do aluno em relação a um dos conceitos basilares de sua pesquisa.

Com efeito, o objetivo de pesquisa definido na versão final do projeto de pesquisa do estudante, exemplificado acima, evidencia-nos que o trabalho está baseado na perspectiva dos gêneros textuais. Contudo, ao definir esse conceito, na Fundamentação Teórica, o mestrando o faz por meio da definição de outro conceito, de gêneros do discurso. A partir do exemplo 1 e outros de nossa investigação de doutorado (FERREIRA-SANTOS, 2020, p. 157), levantamos a hipótese de que o Estudante 1 tomou os dois conceitos como semelhantes, associando-os por um vínculo com baixo grau de abstração. Esse tipo de pensamento associativo, em nosso entender, pode se aproximar do que Vigotski (2009 [1934], p.180) nomeia de pensamento por complexos. Esse modo de pensar se caracteriza, em seu estágio inicial, por uma construção em termos de "nomes de famílias", ou seja, os objetos são agrupados por um "nome de família", porém esse agrupamento não ocorre por um vínculo abstrato e lógico, mas sim, concreto e fatual.

Retomando o quadro acima (Exemplo 1), podemos supor que o estudante compreende os dois conceitos, gêneros textuais e gêneros do discurso, como iguais, pois 
pertencem ao grupo de família "gênero". Ressalta-se que, na versão comentada, o mestrando, antes de definir o conceito, utilizou simplesmente o termo "gêneros".

Na fase intermediária, em inúmeros excertos de nossas análises dos relatórios de qualificação, encontramos uma elevada quantidade de conceitos não maduros (FERREIRASANTOS, 2020, p. 191). Isso pode nos indicar que há vários conceitos cuja aprendizagem é mais complexa e, geralmente, os estudantes apresentam algumas dificuldades de se apropriar de todos os atributos constituintes dos conceitos. Todavia, suas explicações conceituais parecem críveis, quando se analisa de forma superficial. Nesse momento do processo do mestrado, portanto, podemos pensar, com base em Bota (2018, p.226), que os três estudantes apresentam uma "aprendizagem estrutural", isto é, uma aprendizagem que produz novas conexões entre o pensamento e a linguagem, mas somente em limites restritos. Os signos são interiorizados em algumas das suas funções generalizantes e os mestrandos os reconstroem parcialmente.

Vejamos o excerto abaixo, no exemplo 2, que exemplifica vários outros que encontramos em nossa pesquisa e cujos comentários dos orientadores são parecidos.

\section{Exemplo 2 (Estudante 2)}

\begin{tabular}{|c|c|}
\hline \multicolumn{2}{|c|}{ Fundamentação Teórica } \\
\hline Versão comentada & Versão Final \\
\hline $\begin{array}{l}\text { Outro componente constituinte das C de D é } \\
\text { a Situação extralinguística, que se constrói } \\
\text { por meio do ambiente material relativo à } \\
\text { codificação ou à decodificação da } \\
\text { mensagem. Tal ambiente é pertinente ao } \\
\text { fato de que os sujeitos da troca são } \\
\text { possuidores do mesmo saber a respeito do } \\
\text { mundo que os envolve, e por conta disso, } \\
\text { esse ambiente pode ser "transformado em } \\
\text { palavras". [Não está clara a noção. Parece } \\
\text { que a situação extralinguística se refere ao } \\
\text { espaço físico. É só isso mesmo?]. }\end{array}$ & $\begin{array}{l}\text { Ademais, outro componente constituinte } \\
\text { das C de D é a Situação extralinguística, que } \\
\text { se "figura como um ambiente material } \\
\text { transformado em palavra através dos filtros } \\
\text { construtores de sentido, utilizados pelos } \\
\text { atores da linguagem" (CHARAUDEAU, } \\
\text { 2014, p. 32). Assim, esses atores também } \\
\text { criam hipóteses segundo as quais um } \\
\text { determinado ambiente semiotizado está } \\
\text { inserido em um saber partilhado. }\end{array}$ \\
\hline
\end{tabular}

Quadro 2 - Análise da fase intermediária do mestrado

Novamente, assim como em outros exemplos, a interação entre mestrando e orientador gera um segmento do tipo discursivo misto interativo-teórico. Encontramos uma pergunta que remete diretamente a um "diálogo" com o destinatário ("É só isso mesmo?"), 
organizadores lógicos ("Outro", "por conta disso"), modalização lógica ("Não está clara"), anáfora de referenciação intratextual ("Tal", "esse").

No Exemplo 2, representativos de inúmeros outros semelhantes, o mestrando expõe o conceito de "Situação extralinguística" pertencente à teoria Semiolinguística, explicando quais atributos o constituem. Face a isso, o orientador comenta a exposição elaborada, afirmando que ela não está devidamente formulada, como verificamos em "Não está clara a noção". Podemos pensar que, do ponto de vista do orientador, o raciocínio lógico do estudante abarcou somente um aspecto do conceito, porém há outros que se inserem na ideia. Denota-se que o orientador não afirmou que o raciocínio lógico era inválido, mas ele detectou uma instabilidade, a nosso entender típica do pseudoconceito (VIGOTSKI, [1934] 2009).

Ao comentar a exposição teórica do aluno, sugerindo uma modificação na explicação do conceito, levanta-se a hipótese de que o orientador pode ter buscado adequar o conceito não maduro, para que esteja mais alinhado às representações coletivas da teoria Semiolinguística. Verifica-se, na versão final, que o raciocínio foi reelaborado, inclusive trazendo a citação do principal teórico da Semiolinguística sobre o conceito exposto.

Por fim, na última fase da pesquisa, verificamos que os pseudoconceitos ainda persistem nos textos dos três mestrandos. Não obstante, encontramos um exemplo, na versão final da dissertação de mestrado de um dos estudantes (o mesmo do Exemplo 1), a partir do qual levantamos uma hipótese de caracterização singular do momento final do processo do mestrado acadêmico. No excerto abaixo, veremos que o mestrando mostra uma aprendizagem à primeira vista razoável de noções pertencentes a um mesmo sistema conceitual, utilizando-as a fim de produzir um raciocínio comparativo sobre os dados de análise da sua pesquisa.

No quadro abaixo, ilustramos o Exemplo 3, encontrado no texto do Estudante 1. À esquerda, vemos os excertos extraídos do texto do estudante. A direita, propomos uma interpretação do que observamos.

\section{Exemplo 3 (Estudante 1)}

\begin{tabular}{|c|c|c|}
\hline Excerto - Estudante 1 & \multicolumn{2}{|c|}{ Nossa interpretação } \\
\hline "A correção assíncrona realizada por Camila & 1. O Estudante 1 se depara com uma \\
\hline
\end{tabular}


no GoogleDocs ao texto do

gênero fait divers foi diferente de todas as outras feitas pelos outros 5 alunos canadenses $[\ldots]^{\prime \prime}$

"Se usarmos a nomenclatura proposta pelos autores brasileiros Serafini (1989) e Ruiz (2010) que falam sobre correção e que apresentamos em nosso capítulo teórico, podemos chamar seu modo de corrigir de "correção resolutiva". Entretanto, devemos ressaltar que o que foi feito pela aluna canadense não coincide exatamente com a definição desse conceito [...] Enquanto as pesquisas realizadas até então tratam de correções feitas no papel, não há um conceito que corresponda ao que encontramos em nosso corpus, cujos dados foram gerados a partir de ferramentas digitais. $\mathrm{O}$ mesmo acontece com o conceito de "emenda" desenvolvido por Tapia (2016) $[\ldots]^{\prime \prime}$

Poderíamos ter algo parecido em um suporte físico, se pensarmos em uma correção que usa a mesma cor de caneta que o texto original e não usa nenhum outro recurso semiótico para mostrar ao autor daquele texto os contornos da correção. Seu modo de corrigir se configura como uma "correção camuflada". situação-problema (incomum) que foi encontrada nas análises dos seus dados de pesquisa.

2. Após os conceitos terem sido aprendidos pelo Estudante 1, ele não encontra na literatura especializada um conceito adequado para compreender a situaçãoproblema.
3. O Estudante 1 elabora um pensamento original a partir dos conceitos aprendidos.

\section{Quadro 3-Análise da fase final do mestrado}

Nesse raciocínio lógico elaborado pelo estudante não havia nenhum comentário na versão comentada pelo orientador. O raciocínio lógico acima contém marcas, sobretudo, do tipo discursivo teórico, como alta densidade de organizadores lógico-argumentativos ("Entretanto", "Enquanto", "A partir de", entre outros), referência ao intertexto científico ("Se usarmos a nomenclatura proposta pelos autores brasileiros Serafini (1989) e Ruiz (2010) que falam sobre correção", "correção resolutiva", "emenda"), referência intratextual ("que apresentamos em nosso capítulo teórico"), anáforas pronominais e nominais ("seu modo de corrigir", "algo", "como uma correção camuflada").

Parece-nos que o termo "correção camuflada", proposto pelo aluno, pode funcionar como uma retomada sintética de uma generalização, decorrente dos processos de aprendizagem epistêmica acionados ao longo da formação no mestrado. Recuperando os três níveis de aprendizagem epistêmica propostos por Bota (2018, p.226), poderíamos 
arriscar afirmar que constatamos uma "aprendizagem funcional", pois seria possível pensar que o estudante teria adentrado nesse nível de aprendizagem. Recordemos que, conforme expusemos na Fundamentação Teórica, a aprendizagem funcional é uma aprendizagem epistêmica mais consistente, na qual o processo de aprendizagem permite não somente a uma produção de certas conexões localizadas (ou momentâneas) entre o pensamento e a linguagem, porém a uma capacidade contínua de realizar tais conexões, afetando outros conhecimentos interiorizados anteriormente.

Nesse nível de aprendizagem epistêmica, o aprendiz seria capaz de reconstruir um sistema de conceitos aberto, sendo hábil a "ultrapassar" seus atributos, a fim de "realimentar" o sistema conceitual. Por isso, não podemos afirmar que o termo "correção camuflada" é um conceito verdadeiro, pois essa certificação precisa ser realizada pelos especialistas no domínio conceitual apresentado pelo mestrando em sua pesquisa.

Apesar dessas considerações, a análise acima pode significar, possivelmente, um momento de aprendizagem epistêmica entre o tipo estrutural e funcional, isto é, o Estudante 1 pode revelar uma modificação qualitativamente considerável no desenvolvimento de seu pensamento científico.

\section{Considerações Finais}

Como expusemos na Introdução deste artigo, os pesquisadores do ISD se interessam pelo papel das reorganizações psíquicas que provocam e revelam o desenvolvimento humano. Essa ideia advém da perspectiva vigotskiana, na qual as funções psicológicas superiores só podem emergir e se reorganizar, quando o indivíduo se apropria de elementos externos, os quais podem gerar um conflito na organização psíquica.

Aderindo ao escopo das pesquisas do ISD, neste artigo, nosso objetivo era apresentar uma reflexão sobre as potencialidades dos tipos discursivos na compreensão dos efeitos da aprendizagem epistêmica no desenvolvimento de mestrandos em uma formação científica de caráter longitudinal. Justamente, ao optarmos pelo estudo do processo de desenvolvimento, pareceu-nos necessário realizar uma pesquisa de caráter longitudinal, analisando o processo formativo do mestrado, desde seu início até o final, pelos textos nele produzidos. 
Nossos resultados mostram que as interações formativas das versões comentadas, configuradas pelo tipo discursivo misto interativo-teórico, entre os mestrandos e seus orientadores, promovem processos de aprendizagem epistêmica, os quais podem gerar o conflito mencionado no esquema vigotskiano. O conflito, instaurado pela intervenção do orientador, em tipo discursivo misto interativo-teórico, pode propiciar um aprimoramento na capacidade de abstração dos estudantes, para a elaboração de um raciocínio lógico que pode produzir reorganizações dos conceitos já aprendidos e, eventualmente, fazer progredir o pensamento científico em determinado sistema conceitual. Ainda segundo a linha vigotskiana, poderíamos pensar que o processo formativo permitiu a criação de uma zona de desenvolvimento proximal (VIGOTSKI, 2009), propiciada pela intervenção do orientador que, ao instaurar um conflito entre o saber epistêmico que o aluno já tinha e algo novo que desestabiliza esse conhecimento, acaba por provocar uma reorganização psíquica dos saberes.

Por fim, se, como afirma Bronckart (2013), o desenvolvimento pode ocorrer quando há uma reestruturação psíquica positiva, isto é, quando há apropriação-interiorização do debate interpretativo do meio social, podemos dizer que houve um desenvolvimento do raciocínio lógico do estudante, já que este conseguiu pensar dentro do sistema de conceitos que utilizou em sua dissertação, propondo um novo conceito. Nesse sentido, vemos que ele atribuiu novas significações ao debate (no caso, sobre os tipos de correção), propondo uma possível nova significação por meio do conceito de "correção camuflada". Apesar de não podermos afirmar que se trata de um conceito verdadeiro, já que, para tanto, deveria passar pelo exame dos especialistas para sua validação, podemos interpretar que pode se tratar de uma aprendizagem epistêmica funcional, que gera desenvolvimento do raciocínio lógico do aluno.

\section{Referências}

BOTA, Cristian; BRONCKART, Jean-Paul; BULEA BRONCKART, Ecaterina; DESCHOUX, Carole-Anne; DURAND, Marc; PLAZAOLA GIGER, Itziar. Pour une intelligibilité de l'agir au service de la formation et du développement. In: BOTA, Christian; CIFALI, Mireille; DURAND, Marc. Recherche, intervention, formation, travail: Débats et perspectives dans le champ de la formation des adultes. Genève: Cahiers de la section des Sciences de l'éducation (Université de Genève), 2006, p. 83-110. 
BOTA, Christian. Pensée verbale et raisonnement: les fondements langagiers des configurations épistémiques. 1.ed. Berna: Peter Lang, 2018. 262p.

BRONCKART, Jean-Paul. Atividade de linguagem, textos e discursos: por um Interacionismo Sociodiscursivo. 2.ed. Tradução: Anna Rachel Machado e Péricles Cunha. São Paulo: Educ, 1999. 353p.

BRONCKART, Jean-Paul. Atividade de linguagem, discurso e desenvolvimento humano. 1.ed. Tradução: Anna Rachel Machado e Maria Lucia Meirelles Matêncio. Campinas: Mercado de Letras, 2006. 259p.

BRONCKART, Jean-Paul. Une science du langage pour une science de l'humain. In: Actes du $1^{\circ}$ Congrès mondial de linguistique française, p. 47-60, 2008

BRONCKART, Jean-Paul. Um retorno necessário à questão do desenvolvimento. In: BUENO, Luzia; LOPES, Maria Ângela Paulino Teixeira. Gêneros textuais e formação inicial. Campinas: Mercado de Letras, 2013, p. 85 -108.

BULEA, Ecaterina; BOTA, Christian; BRONCKART, Jean-Paul. L'épistémologie nébuleuse de l'autoformation. Education permanente, n. 168, p. 31-57, 2006.

BULEA, Ecaterina; BRONCAKRT, Jean-Paul. As potencialidades praxiológicas e epistêmicas dos (tipos de) discursos. SCRIPTA, Belo Horizonte, v.22, n.12, p. 42-83, 2008.

BULEA, Ecaterina. Linguagem e Efeitos desenvolvimentais na interpretação da atividade. Campinas: Mercado de Letras, 2010. 176p.

FERREIRA-SANTOS, Thiago Jorge. Textos, aprendizagem e desenvolvimento do pesquisador no processo formativo do mestrado acadêmico. 2020. Tese (Doutorado em Letras) - Faculdade de Filosofia, Letras e Ciências Humanas, Universidade de São Paulo, São Paulo.

FRIEDRICH, Janette, HOFSTETTER, Rita, SCHNEUWLY, Bernard. Théories du développement: controverses pédagogiques, conceptuelles et politiques à l'aube du XXe siècle. In: FRIEDRICH, Janette, HOFSTETTER, Rita, SCHNEUWLY, Bernard. Une science du développement humain est-elle possible? Controverses du début du XXe siècle. Rennes: Presses Universitaires de Rennes, 2013, p. 9-24.

LEONTIEV, Alexis Nikolaevich. Os princípios do Desenvolvimento Mental e o Problema do Atraso Mental. In: VYGOTSKYI, Lev Seminovitch et al. Psicologia e Pedagogia. São Paulo: Centauro Editora, 2005, p.87-105.

SANTOS, Thiago Jorge Ferreira. A linguagem revelando o desenvolvimento do pesquisador na Iniciação Científica. 2016. Dissertação (Mestrado em Letras) - Faculdade de Filosofia, Letras e Ciências Humanas, Universidade de São Paulo, São Paulo. 
SCHNEUWLY, Bernard. La notion de développement revisitée dans la perspective d'enseignement (scolaire) et de formation (des adultes). In: BERNIÉ, Jean-Paul; BROSSARD, Michel. Vygotski et l'école: apports et limites d'un modèle théorique pour penser l'éducation et la formation. Pessac: Presses universitaires de Bordeaux, 2013, p. 309-325.

VOLOCHÍNOV, Valentin Nikolaevič. Marxisme et philosophie du langage : Les problèmes fondamentaux de la méthode sociologique dans la science du langage. Tradução: Patrick Sériot; Inna Tylkowski-Ageeva. Limoges: Lambert Lucas, 2010.

VYGOTSKYI, Lev Seminovitch. Psicologia Pedagógica. 2.ed. Tradução: Paulo Bezerra. São Paulo: Martins Fontes, 2004. 561p.

VYGOTSKYI, Lev Seminovitch. A formação social da mente. 7.ed. São Paulo: Martins Fontes, 2007. 182p.

VYGOTSKYI, Lev Seminovitch. A Construção do pensamento e da linguagem. Tradução: Paulo Bezerra. 2.ed. São Paulo: Martins Fontes, 2009. 496p.

VYGOTSKYI, Lev Seminovitch. El significado histórico de la crisis de la Psicologia: Una investigación metodológica. In: VIGOTSKI, Lev Seminovitch. Obras Escogidas I: EI significado histórico de la crisis de la Psicologia. Una investigación metodológica. Madrid: Editorial Pedagógica, 2013, p.257-407.

\footnotetext{
' Doutor em Letras (Estudos Linguísticos) (USP); Membro do grupo de pesquisa ALTER-AGE (CNPq/USP). E-mail: thiagojorgefs@gmail.com

ii Doutora em Linguística Aplicada e Estudos da Linguagem (PUC/SP); Professora do Departamento de Letras Modernas (FFLCH/USP); Pesquisadora CNPq-2; Líder do grupo de pesquisa ALTER-AGE (CNPq/USP).

E-mail: elousada@usp.br
} 